\title{
Robert A. Cummins: Pioneer on Subjective Wellbeing Homeostasis
}

\author{
Robert A. Cummins
}

Received: 1 December 2013 / Accepted: 28 December 2013 / Published online: 14 January 2014 (C) Springer Science+Business Media Dordrecht and The International Society for Quality-of-Life Studies (ISQOLS) 2014

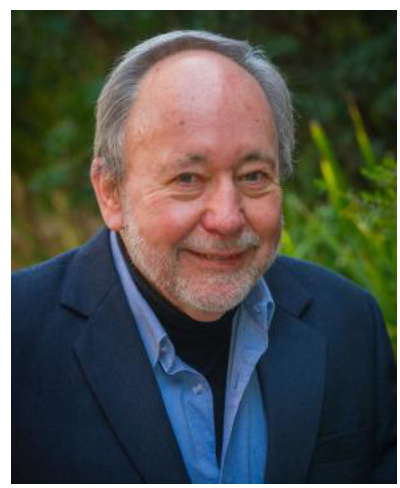

My academic career commenced in 1973 as part-time demonstrator in physiology at the University of Queensland. This was followed by a fixed-term lectureship in psychology at the University of Western Australia from 1976 to 1978. During this period my research was in neurophysiology I completed my doctorate in this area.

$\mathrm{PhD}$ completed, and a young family in tow, I needed a tenured position. So we moved to Melbourne where I became Senior Lecturer at a small teaching college in the area of disability. My research now took a different path and over the next decade my attention was directed to intellectual disability. Then my research life changed again. A colleague casually asked if I might be interested in some collaborative research. He described it as being in the area of 'quality of life', working with a couple of researchers from Melbourne University.

I reflexively said 'yes!', and only then reflected that I had no idea what this research area involved. Neither did I realize that I had elected to join two of the most outstanding researchers of their time in the area of subjective wellbeing (SWB). Alex Wearing and Bruce Headey were the first researchers to publish longitudinal results showing that 
SWB was not only surprisingly stable but also that, after it changed due to some major life event, it tended to gradually return to its earlier level. Their 'equilibrium model' greatly influenced my thinking and led me to the idea of homeostasis theory, which I have been developing ever since.

In trying to understand this new area I was heavily influenced by my training in physiology. This had given me a very reductionist approach to information processing and so I was discomforted viewing SWB research through this particular lens. While a number of scales were in use for this form of measurement, they seemed to lack an empirical reference point for understanding the meaning of the results. So, I started to play with the most reliable data I could find in the literature, which were the mean scores from population samples. I started this game by creating a simple formula which converted the result from any response scale onto a standard 0-100 range. I called this new metric 'percentage of scale maximum'. Then, armed with my new device, I started converting my collection of population SWB mean scores.

The memory of my "eureka moment" is vivid. I had noticed considerable consistency in the numbers my formula was producing. Despite different kinds of measurement scales and different countries, the mean values tended to lie between 70 and 80 points. I resolved to myself that, if the next conversion from the next randomly-chosen paper also lay within this range, I would have discovered some kind of a standard. As I opened my eyes after pressing the compute button, the value was 76.5 and I screamed. Not only that, I leapt to my feet. Bad move.

It was summer in Melbourne and I was home alone with Puddykins, my cat, who had assumed her customary sleeping position on my lap when I was working. Due to the heat, I was wearing only underpants with a thin cotton cloth across my lap to accommodate the sleeping cat. My scream energized her escape response while my sudden verticality left her suspended in space. So with feline-turbo-charged reflexes, she arrested her descent by applying all 20 claws into the only available surface-me. Another scream, this time coupled with invective. So intense was this commotion that my neighbor, on the other side of the thin terrace house wall, later knocked on my front door to check if I was OK. My explanation was less than adequate.

My subsequent research over the past two decades has built on this empirical foundation (Cummins 1995, 1996), with the development of Homeostasis Theory (Cummins 2010) to account for SWB stability and, most recently, an empirical demonstration of SWB set-points (Cummins et al. 2013). Impending retirement from paid employment at the end of 2013 signals a new chapter in life as an honorary professor at Deakin with an undiminished determination to follow the instruction I give my graduate students. "Our mission", I tell them, "is to discover why homeostasis theory is wrong before anyone else".

\section{Selected Publications}

Cummins, R. A. (1995). On the trail of the gold standard for life satisfaction. Social Indicators Research, 35, 179-200. 
Cummins, R. A. (1996). The domains of life satisfaction: an attempt to order chaos. Social Indicators Research, 38, 303-332.

Cummins, R. A. (2010). Subjective Wellbeing, Homeostatically protected mood and depression: a synthesis. Journal of Happiness Studies, 11, 1-17. doi:10.1007/s10902-009-9167-0.

Cummins, R. A., Li, N., Wooden, M., \& Stokes, M. (2013). A demonstration of set-points for subjective Wellbeing. Journal of Happiness Studies. doi:10.1007/s10902-013-9444-9. 